Cadernos de História, Belo Horizonte, v. 22, n. 36, Junho de 2021

DOI: https://doi.org/10.5752/P.2237-8871.2021v22n36p9-23

\section{DisCURSOS HIGIENISTAS PARA A EDUCAÇÃo PRIMÁRIA NO PARÁ (1900-1912)}

Darlene da Silva Monteiro Universidade do Estado do Pará darlene.monte@hotmail.com

Mario Allan da Silva Lopes Universidade do Estado do Pará m.allanlopes@gmail.com

José Arimatéa G. Dos SANTos Universidade Federal do Pará ari.gouveia@hotmail.com

\title{
Resumo
}

Este artigo tem como objetivo analisar como os discursos higienistas permearam as práticas e orientaram o ensino, de forma a legitimar um padrão higienista para educação primária do Pará no período de 1900-1912. É uma pesquisa documental que analisou documentos históricos como o relatório do $4^{\circ}$ grupo escolar (1909), o jornal Província do Pará (1910), jornal Folha do Norte (1910), mensagem do governador do estado do Pará (1897), revista A Escola (1900) e da Revista do Ensino (1911). Para dialogar com as análises, trazemos para o debate autores como Coelho (2002), Habib (2012), Foucault (1986), Mendes e Nobrega (2008), entre outros. A partir das análises das fontes entendemos que os discursos higienistas moldaram o que seria considerado ideal para as escolas. Desde as construções dos prédios escolares até a organização escolar, os discursos desses médicos e sanitaristas perpassaram por consideráveis debates educacionais no estado do Pará, construindo um modelo de educação saudável e moderno, evidenciando assim uma grande discrepância social.

Palavras-chave: Ensino primário; Higienismo; Discursos Científicos.

Recebido em 25 de agosto de 2020.

Aprovado em 12 de novembro de 2020. 
Cadernos de História, Belo Horizonte, v. 22, n. 36, Junho de 2021

DOI: https://doi.org/10.5752/P.2237-8871.2021v22n36p9-23

\section{HYGIENIST SPEECHES FOR PRIMARY EDUCATION IN PARÁ (1900-1912)}

Darlene da Silva Monteiro Universidade do Estado do Pará darlene.monte@hotmail.com

Mario Allan da Silva Lopes Universidade do Estado do Pará m.allanlopes@gmail.com

José Arimatéa G. Dos SANTos Universidade Federal do Pará ari.gouveia@hotmail.com

\begin{abstract}
This article aims to analyze how hygienist speeches were present in educational practices and guided teaching, in order to constitute a hygienist standard for primary education in Pará in the period between 1900-1912. It is a documentary research that analyzed historical documents such as the report of the 4th school group (1909), the newspaper Província do Pará (1910), newspaper Folha do Norte (1910), message from the governor of the state of Pará (1897), the magazines A Escola (1900) and Revista do Ensino (1911). To have a dialogue with the analyzes, we bring to the debate authors such as Coelho (2002), Habib (2012), Foucault (1986), Mendes and Nobrega (2008), among others. From the study of the sources we understand that the hygienist speeches shaped what would be considered ideal for schools. From the construction of school buildings to the school organization, the speeches of these doctors and sanitarians went through important educational debates in the state of Pará, building a healthy and modern education model, thus showing a great social difference.
\end{abstract}

Keywords: Primary education; Hygienism; Scientific Speeches. 


\section{INTRODUÇÃo}

O presente trabalho é fruto de uma pesquisa sobre a educação primária na primeira república paraense, na qual nos deparamos com fontes que fortificavam a imagem da educação como o berço da República, de onde nasceriam os futuros cidadãos republicanos do Pará. Sendo assim, vários foram os agentes externos que influenciavam a educação com fins de civilizar e normalizar hábitos e comportamentos da criança, desde os anos iniciais da escola. Um desses agentes eram os médicos e sanitaristas que faziam ecoar, na legislação e na imprensa destinada à educação, discursos higienistas que viriam a definir as ações escolares, as matrículas dos alunos, as práticas pedagógicas e a infraestrutura do prédio escolar.

Este trabalho pretende analisar como os discursos higienistas permearam as práticas e orientaram o ensino, de forma a legitimar um padrão higienista para educação primária do Pará no período de 1900-1912. Especificamente, detém-se em discutir as interlocuções que se estabeleciam entre os discursos higienistas produzidos por médicos e sanitaristas e o contexto das transformações sociais implantadas com o advento da República no Pará; bem como identificar as formas de circulação e apropriações desses discursos na orientação das práticas escolares da educação primária fundamental e descrever a atuação dos discursos higienistas como única forma de progresso nas orientações dos espaços escolares.

A pesquisa é do tipo documental e apoia-se na pesquisa bibliográfica para dar conta de analisar as fontes documentais coletadas. A pesquisa de natureza documental foi realizada no Arquivo Público do Estado do Pará. Lá, encontramos relatórios dos diretores dos grupos escolares e a legislação vigente.

A Biblioteca Arthur Viana (CENTUR), em Belém, tornou-se um local onde encontramos fontes inéditas, localizadas no Setor de Microfilmagem, onde foi realizada a pesquisa nos jornais Folha do Norte e Província do Pará. Além desses espaços, destacamos o Fórum Landi, instituição ligada à Universidade Federal do Pará, onde pudemos recorrer a um vasto acervo de periódicos, dentre eles, os utilizados para a constituição deste trabalho, como as edições da revista pedagógica $A$ Escola.

Para este trabalho, trouxemos para análise algumas fontes, como o relatório do $4^{\circ}$ Grupo Escolar (1909), os jornais Província do Pará (1910) e Folha do Norte (1910), Mensagem do Governador do Estado do Pará (1897), a Revista A Escola (1900) e a Revista do Ensino (1911). Para dialogar conosco, trouxemos autores como Coelho (2002), Habib (2012), Foucault (1986), Mendes e Nobrega (2008), entre outros.

A presença de discursos de higienistas na imprensa pedagógica, bem como em jornais e até em decretos e regulamentos oficiais do Estado do Pará dos anos finais do século XIX e anos iniciais do século XX, escritos por médicos, nos faz problematizar sobre quais foram as condições que favoreceram um saber cientificista vindo da Europa e que conseguiu se difundir na Amazônia, especificamente na educação no Estado do Pará.

\section{Higienismo e a República no Pará}

A República no Pará em 1889 demarcou um período de transformações de cunho social, político, jurídico, administrativo, principalmente, nos grandes centros urbanos, como foi o caso de Belém. Os hábitos, valores e costumes da corte imperial aos poucos foram substituídos 
por novos valores e ideias consideradas científicas. A cultura política e a defesa de valores nacionalistas, de liberdade e prosperidade ganhavam espaço nas aspirações de uma nova sociedade. De acordo com Farias (2013, p. 186), “os republicanos defendiam uma ideologia do 'progresso', na qual o regime defendido seria o princípio racional e fundamental" para a sociedade almejada.

A educação primária no Pará, no início do regime republicano, vivenciou um momento de profundas transformações em virtude do contexto republicanista em que se encontrava o estado. Tal contexto trazia questões sobre ciência, progresso e positivismo, pontos que colocavam a ciência como única forma de progresso para uma nação que se estabelecia, dando, assim, visibilidade para as produções dos 'homens das ciências', que eram os médicos e os sanitaristas (SANTOS, 2018).

Priore (2017, p. 21) discute que o sentimento de reorganização do espaço público brasileiro trouxe a ideia de que o desenvolvimento de políticas públicas voltadas para o saneamento das cidades garantiria o progresso do país. Para os republicanos, "bastava europeizar-se e adotar métodos científicos nas escolas, cidades, prisões” para se ter uma sociedade limpa, sadia, culta e civilizada.

Gondra (2005, p.2) salienta que a ordem médica produziu representações na cidade como "feia, suja, fétida, insegura, doente, negra, imoral e iletrada". Essa realidade fez com que a ordem médica formulasse projetos de formação para o indivíduo que habitava essa cidade. Esses projetos seriam, de acordo com Gondra (2005), desenvolvidos pela escola, que iria não apenas escolarizar a sociedade, mas implementar um "prontuário" de boas condutas sociais.

De acordo com Sarges (2010), a criação de uma moral educadora se estabeleceu enquanto postura reguladora do Estado, que via, na população, o seu suporte para a concretização de ações reguladoras, implementando um controle rigoroso dos comportamentos daqueles que habitavam a capital.

Sobre essa questão, Stephanou (2011) evidencia que, nos anos finais do século XIX e nos anos iniciais do século XX, no Brasil, houve uma grande movimentação acerca de discursos que tomavam como pauta a medicina social, legitimada por aspectos científicos, moralizadores e salvacionistas. Tais aspectos fortificavam as aspirações sociais pretendidas com a República e se impuseram em meio às discussões de "Modernizar, regenerar, civilizar, dar ao povo saúde e educação" (STEPHANOU, 2011, p. 147). Nesse contexto, os médicos destacavam-se em meio às transformações sociais como "arautos" de uma mudança não apenas na educação da população, mas no espaço social.

Quanto a esse ponto, a educação tornou-se a forma propícia para a difusão da ciência por meio dos discursos desses homens, que traziam questões que ratificavam o pensamento moral e eugenista. A tônica dos discursos figurava em torno de uma educação no Pará com ênfase na pátria e no progresso do Estado, que aspirasse à civilidade mediada pelos padrões da modernidade (SANTOS, 2018).

A República, de fato, assegurou um terreno fértil para que os discursos científicos higienistas delineassem a educação paraense nos anos iniciais da República no Pará. Esses discursos tinham, entre suas propostas, reger as práticas educacionais, os conteúdos escolares, o comportamento das crianças, além de idealizarem a forma como esse ensino deveria ser organizado estruturalmente, de modo a trazer para os paraenses um novo perfil social, 
precisava-se formar o "republicano paraense", apto fisicamente e cumpridor de seus deveres pátrios.

O higienismo defendido pelos médicos apresentava base científica e, assim, além de ser um saber racional, tinha sua proposta prática "de predizer os acontecimentos e indicar meios de auxiliá-los ou impedi-los, conforme o caso”, segundo assinalam Mendes e Nóbrega (2008, p. 210). Nesse sentido, as ciências modernas, "alicerçadas no método positivo", atuavam com previsibilidade aos fenômenos naturais, podendo, no caso das doenças, não só diagnosticálas, como até preveni-las (MENDES; NÓBREGA, 2008, 211).

Desse modo, para um estado que pretendia formar um batalhão de cidadãos ligados, na 'mente' e no 'coração', à pátria por meio de instituições de ensino, as quais deveriam ser os locais de ensino apropriado que evitaria, em meio ao agrupamento de educando, a propagação de epidemias tão comuns entre as populações dos séculos XIX e XX (LOPES, 2018).

$\mathrm{Na}$ educação paraense, esses discursos ganharam força por meio dos ideais médicos propagados nos jornais e impressos pedagógicos oficiais, ligados à administração pública do estado. Com relação aos impressos pedagógicos que assumiam essa função, citamos a revista A Escola, que circulou no período de 1900 a 1905 e a Revista do Ensino, que circulou nos anos de 1911 e 1912. Essas revistas destinavam-se à orientação das práticas pedagógicas dos professores e divulgação das ações das escolas do Pará (SANTOS, 2018).

Esses impressos pedagógicos se apresentavam como 'instâncias educativas', e eram visualizados pelos intelectuais da época como o terreno fértil e propício para (re)produzirem discursos, teorias e pensamentos políticos. As apropriações desses discursos davam-se pela circularidade desses impressos nas escolas do Pará, onde os professores da educação paraense tinham a possibilidade de, igualmente a esses intelectuais, manifestarem-se nesses impressos (SANTOS; FRANÇA, 2020).

Esses discursos giravam em torno da valorização do espaço público em termos estruturais, da higiene social, da higiene escolar, assim como em torno das regras de boa conduta pública, comportamentos sociais, entre outros assuntos que buscavam construir uma nova concepção de homem que viesse a desenvolver os compromissos cívicos com seu Estado e sua pátria.

A imprensa educacional assumiu um importante papel frente aos debates educacionais que marcaram a sociedade paraense nas primeiras décadas do regime republicano no estado. Por meio da imprensa, foi possível compreender as concepções de ciências e educação defendidas por intelectuais, na sua maioria médicos e personalidades da administração pública do Pará, que publicavam seus artigos nesses impressos, com vistas a criar uma representação sobre sociedade e educação civilizada.

Baseados nessas concepções, os médicos viam na educação paraense o caminho para assentar a propaganda da higiene escolar como um saber necessário na Educação Primária do Pará. Esses discursos são divulgados, ou melhor, passam a aparecer como objeto, por estarem "sob as condições positivas de um feixe complexo de relações", numa perspectiva de Foucault (1986, p. 51). Nesse caso, podemos considerar os elementos dessas relações: o uso da imprensa ${ }^{1}$ destinada à educação para a divulgação da pedagogia higienista; a presença do governador Paes de Carvalho, chefe do Estado do Pará, que, entre suas ações políticas, buscou favorecer a implantação das novas ideias modernas na educação.

José Paes de Carvalho, durante seu mandato de 1897 a 1891 como governador do Pará, 
promoveu políticas para a implantação de propostas pedagógicas modernas que incluíam, entre outras ações, as ciências como um saber privilegiado (SANTOS; ALVES, 2014; SOUSA, 2015; LOPES, 2018).

No início de seu governo, em Mensagem enviada ao Congresso em 1897, podemos ver os registros da política de educação para o estado, em que as ciências estavam evidenciadas como parâmetro de condução do ensino: "Muito há a esperar do vastíssimo plano de ensino, que vigora entre nós. Preside à sua organização elevado critério científico e técnico” (PARÁ, 1897, p. 27).

A proposta das ciências como critério de instrução foi inserida na crença de progresso do Estado por uma trajetória linear de abandono das práticas educativas baseadas nas humanidades, pelo ensino moderno, dirigida aos educandos. Esses, por sua vez, ao se apropriarem do novo saber, aplicá-lo-iam à vida, ao invés de possuírem uma coletânea de conhecimentos que consideravam não serem utilitárias ao desenvolvimento da sociedade.

\footnotetext{
Orienta-se a intervenção dos governos pelos progressos que tem feito o ensino moderno, cuja característica é proporcionar aos educandos todos os meios que os familiarizem com as verdades da ciência e seus preceitos de mais útil aplicação na existência prática. (PARÁ, 1897, p. 27).
}

A valorização dos preceitos científicos na educação por meio de práticas higienistas difundidas na imprensa e destinadas à educação não se apresentava como um texto isolado sem relações estabelecidas com instituições, sem movimento com o social e o econômico, sem atender normas e modos de caracterização, pelo contrário, estava na ordem do discurso, na perspectiva foucaultiana (1986). Ainda que o objeto higiene escolar, tão em voga nos anos iniciais da República no Pará, pudesse "dizer alguma coisa”, ele estava em condições de ser dito, naquele momento histórico, por se inscrever "em domínio de parentesco com outros objetos", para que pudesse "estabelecer com eles relações de semelhança, de vizinhança, de afastamento, de diferença, de transformação” (FOUCAULT, 1986, p.51).

\section{Ciência, Educação e Civilização}

O ideário republicano, nutrido pelo pensamento científico, colocava as ciências e suas práticas como capazes de aprimorar a sociedade, ao promover o progresso por meio da racionalidade e assimilação de ordenamento científico, pontos essenciais para a busca por sujeitos melhores.

Para Hofbauer (2006, p. 99), o perfil de "homem virtuoso" foi algo evidenciado nas discussões cientificistas ocorridas durante o século XIX, período de maior efervescência sobre a valorização das características biológicas dos indivíduos, o que, de acordo com o autor, trouxe à baila um movimento de transformações do conceito de raça em categoria científica, assim "o conceito 'raça' surgiria como uma nova referência conceitual possível para pensar diferenças humanas”.

Nessa ótica, essa de acordo com (HOFBAUER, 2006, p. 118) “biologização das diferenças” surgiu em virtude das lentas transformações que o homem teve na visão de si mesmo, do outro e do mundo em que vive. As aspirações religiosas de atingir o paraíso dão vasão ao desejo do alcance do sucesso terreno, ao passo que a "crença na razão, a crença na força da 
natureza e a crença no progresso", serviriam de bases para pensar o mundo e orientar os parâmetros de avaliação das diferenças humanas (HOFBAUER, 2006, p. 118). Foi em meio a esse discurso que a educação se tornou uma das principais aliadas na implementação do projeto civilizatório republicano.

De acordo com Coelho (2002), a questão do progresso atrelava-se ao modo de vida civilizada, característica básica de representação e assertiva do mundo burguês. A ideia de homem civilizado e protagonista do progresso social partia de sua própria constituição, advinda do entrelaçamento de uma cadeia polissêmica de significados, traduzidos de forma estética, pelo bem 'vestir-se' e pelo bem 'portar-se', ao mesmo tempo em que esse homem se submetia aos discursos doutrinários da ciência positiva, pensamento capaz de trazer novos rumos para a sociedade.

Na compreensão de Coelho (2002), o progresso vivenciado pela capital paraense não traduzia apenas os avanços na cultura material, mas, de alguma forma, refletia avanços nos processos de modernização da sociedade, que iam desde o aperfeiçoamento político, assim como o das instituições. Esse movimento reproduziu o ideário político francês, acentuando um processo polissêmico cultural que se espalhava por todo o país, como formas representativas de um progresso político que se se solidificava sob bases positivistas, alcançando um progresso não somente político, mas moral, algo que diferenciava a República do regime político anterior.

Todo esse cenário político refletia uma certa identidade do que era ser republicano no Pará, como bem esclarece Coelho (2002, p. 18), "ser republicano, deste ponto de vista, era estar em sintonia com as pulsações aceleradas de um tempo de transformações”. Para esse autor, atrelar-se ao que vinha ocorrendo significava assumir uma postura civilizada, sendo, então, a civilização vista como parte do processo de desenvolvimento do espírito humano.

Para Elias (1994, p. 23), essa forma de ver-se "civilizado" ou "incivilizado" atrela-se ao modo como a sociedade ocidental se coloca diante de si mesma, visto que "a sociedade ocidental procura descrever o que lhe constitui o caráter especial e aquilo de que se orgulha". Sendo assim, o conceito de homem civilizado passa a refletir a imagem do modelo que lhe foi colocado como superior. No caso paraense, o modelo de educação formulada e disseminada seguia os moldes pedagógicos franceses e norte-americanos, e buscava implementar o perfil de homem que essas nações refletiam.

$\mathrm{O}$ anseio pelo progresso social movimentou a produção intelectual paraense desde os anos finais do século XIX. De acordo com França (2004), os intelectuais brasileiros, movidos pelas "luzes francesas", viam na educação a saída para aperfeiçoar os homens, conquanto essa autora frise que esses intelectuais lançaram mão de uma multiplicidade de teorias para formularem seus projetos educativos, "atingir os marcos do progresso científico das sociedades modernas estaria na dependência direta da renovação cultural, da reforma do ensino e do aperfeiçoamento da instrução pública” (FRANÇA, 2004, p. 42).

Sá (2006) aponta que os discursos dos homens da ciência não foram responsáveis por inaugurar uma atividade científica no país, mas se efetivaram como uma variação nas formas e modos de se produzir ideias no país. A partir dessa análise, o que não pode deixar de ser considerado é a forma como ocorre a especialização da atividade intelectual no Pará. A produção intelectual se apresentou nos anos finais do século XIX e início do século XX como 
o seguro e sensato caminho da atividade científica, e como atividade intelectual necessária para constituição do novo social no estado.

Destacamos que, desde 1897, a sociedade paraense começou a ter o seu espaço reordenado e disciplinado, sobretudo a capital Belém, que vivenciava um "embelezamento do visual da cidade" (SARGES, 2010, p.152), onde o intendente municipal Antônio Lemos passou a adotar uma política sanitarista para a cidade, com o objetivo de zelar pelo bem-estar social e cuidar do estilo de vida urbano. A proposta era garantir saneamento, saúde e uma boa estética para a capital, para isso, eram necessárias medidas para conter os maus hábitos da sociedade indisciplinada e fétida. Entre essas medidas, destaca-se o "Código de Postura", implementado em 1900 (SARGES, 2010).

Foi em meio a esse cenário que a ciência buscou alargar suas fronteiras no âmbito educacional no Estado do Pará. O conceito e modo de vida científicos chamam a atenção da intelectualidade paraense, não é à toa que médicos, como Acylino de Leão ${ }^{2}$ e Lyra Castro ${ }^{3}$, foram homens que atuaram energicamente não apenas como médicos, mas como políticos em cargos de relevo na República. Esses homens viam, na educação, um caminho promissor para difundir suas teorias. O status de 'Sociedade Civilizada' estava em jogo, a esses homens, restava-lhes cumprir a execução do projeto civilizatório para a sociedade paraense.

$\mathrm{Na}$ educação, os republicanistas paraenses buscaram moldar comportamentos, mudar conceitos, educar corpos e mentes capazes de assegurar uma sociedade forte, culta, moralizada e voltada para o comprometimento com sua nação. Todavia, as mudanças não foram fáceis, mais do que moldar comportamentos, a mudança de mentes e concepções foi mais difícil do que se poderia imaginar. Era necessário levar ao entendimento das crianças amazônicas a concepção do novo homem civilizado, não mais rude e sim com uma visão superior de si.

Nesse ponto, o pensamento científico foi decisivo, e muitos médicos foram os portavozes da ciência na educação, entre esses homens, destaca-se Acylino de Leão, médico que, ao discutir sobre a Higiene Social na edição de no 2 da Revista do Ensino de 1911, trouxe pontos dos estudos de Charles Darwin, para defender a superioridade humana, como condicionante na obtenção de comportamentos higiênicos e cultos. Para esse médico, o homem ocupa o lugar mais alto da escala zoológica, contudo deveria fazer jus à posição evolutiva. Essa imposição à natureza exigiria novos comportamentos, formas que lhe concedessem o "status" de "rei da criação”. Sobre essa questão, Leão (1911, p. 17) apontava que:

2 Acylino de Leão Rodrigues (1882-1950) se posicionou como intelectual de destaque ao trazer discussões sobre a Higiene Escolar para o ensino no estado. Nascido em 17 de julho de 1882 em Macapá, território ainda incorporado ao Pará, formou-se, inicialmente, em Farmácia e, em seguida, em Medicina na cidade do Rio de Janeiro em 1908. Em busca de amadurecimento profissional, seguiu para Portugal e Franca, onde fez estágio em Paris na Clínica Necker e, somente em 1909, retornou a Belém para o exercício de sua profissão como médico. Foi professor e diretor da Faculdade de Livre Direito e da Faculdade de Medicina. Atuou ainda como médico, político, homem de letras, jornalista, parlamentar e colaborador da Revista do Ensino do Pará (REGO, 1986). (MEIRA, 1986. MÉDICOS DE OUTRORA NO PARÁ).

3 Germiniano de Lyra Castro (1863-1936) nasceu em Igarapé-Miri, no estado do Pará, em 1863, fez seus estudos primários em Belém e cursou Medicina em faculdades da Bahia e Rio de Janeiro, especializando-se em oftalmologia. Exerceu o ofício de médico, foi Inspetor de Higiene do Estado do Pará, diretor do Hospício de Alienados, professor da Faculdade de Livre Direito do Pará e da Faculdade de Medicina. Na carreira política, exerceu cargos como os de Conselheiro Municipal de Belém, Vice-Governador no mandato de Augusto Montenegro no Pará (1901-1904), Senador Estadual e Presidente do Senado, Deputado Federal (1918-1926). Foi Ministro da Agricultura no Governo de Washington Luiz (1926-1930), além de colaborador da revista A Escola (MEIRA, 1986. MÉDICOS DE OUTRORA NO PARÁ). 
O selvagem volúvel como crianças, não tem ainda a tenacidade do querer, mas as raças civilizadas demonstram a sua fortaleza justamente por essa união de esforços sustentados, a que as nações fracas têm a ceder [...].

Ao mesmo passo que se desenvolve a inteligência pela cultura, e se educa a sensibilidade pelo exemplo da virtude e pelo visionamento da beleza, amestra-se à vontade pela ação.

O médico é enfático ao considerar que o homem selvagem se compara a uma criança que ainda não compreende o sentido e significado de suas ações e que, para obter a elevação de sua consciência superior, precisa ceder e lutar contra seus instintos. O pensamento desse médico aponta como, por meio da ciência, é possível apresentar às crianças uma educação higienizada, capaz de modificar não somente o corpo, mas a mente. O desenvolvimento da inteligência cultural se coloca para Leão (1911) como ponto chave da boa educação, uma mente educada é capaz de moldar o corpo do homem que se busca o homem civilizado.

Os discursos higienistas propagados por médicos nos anos iniciais da República no Pará foram responsáveis pela reestruturação da educação no estado, ditando regras para as matrículas de crianças no ensino público, normalizando comportamentos de alunos e professores quanto ao cumprimento do "asseio" pessoal, bem como ao uso do espaço escolar, entre outros assuntos.

Esses discursos assentavam-se na legislação educacional, como os Decretos de no 625 de 1899 e no 1190 de 1903, que estabeleciam os Regulamentos do Ensino Primário, o Relatório da Instrução Pública de 1910, como um prontuário médico, receitado ao paciente doente, que, naquele momento, requeria cuidados e um olhar atento às suas ações. $O$ paciente, nesse caso, era a educação primária paraense, que, nos discursos desses homens, precisava ter bem mais que um caráter pedagógico, mas um caráter científico sobre as ações das crianças.

Para Stephanou (2011), os discursos sobre a educação sanitária na escola brasileira evidenciam que, nas primeiras décadas do século XX, a ciência médica se colocava na defesa de uma educação pautada nos preceitos científicos da medicina e de como esses preceitos poderiam reformular as práticas escolares para um progresso não somente da escola, mas da aprendizagem das crianças. De acordo com a autora, essa comunidade médica avaliava a educação como 'obsoleta' na sua organização estrutural, curricular, administrativa e pedagógica e de baixo interesse para os pequenos aprendizes.

Dessa forma, foi exatamente movido por esses pensamentos científicos que Castro (1900) iniciou suas colocações sobre a higiene escolar, temática muito em evidência na sociedade da época. Convém-nos aqui destacar que a sociedade paraense, nos anos iniciais da República, estava comprometida pela inexistência dos preceitos de higiene, essa ausência colocava em risco homens e mulheres que habitavam moradias insalubres e até mesmo as crianças que frequentavam espaços precários, onde as escolas funcionavam.

Castro (1900), ao tratar sobre padrões de higiene na estrutura e práticas pedagógicas no Pará, escreveu, em 1900, para a revista A Escola de no 2, o artigo "Higiene Escolar", em que enfatizava a importância de uma sociedade higienizada para o alcance de patrões civilizados, como condição de elevação da nação para a pátria que se estabelecia. $O$ apontava ainda que o definhamento da sociedade escolar paraense se dava pela ausência da Educação Física nas práticas escolares, algo que enfraquecia não somente o corpo, como também o espírito pátrio do sonhado cidadão. 
Os debates de Castro (1900) traduziam sua preocupação com o cuidado e com o zelo referentes ao corpo das crianças que se constituiriam os novos cidadãos da nação. Esse zelo alcançava ainda o ambiente escolar, local onde a nova estrutura de escola, defendida por ele, iria funcionar. A tese abraçada era a de que o ensino público no Pará precisava avançar, mas de forma organizada, em respeito aos padrões ditados pela ciência, prezando pelo cuidado com o corpo, espírito e espaço físico. Sobre esse cuidado e atenção em relação à escolha das casas, Castro (1900, p. 23), assim, os define:

A escola é o centro de reunião de centenas de crianças que aqui vão em busca de instrução e onde passam maior parte dos dias.

E, por conseguinte, de fácil intuição, que o primeiro cuidado do higienista deve versar sobre a construção do prédio destinado à escola.

O entendimento do espaço escolar como algo que não poderia ser organizado ou escolhido à revelia nutria-se das concepções científicas higienistas de pensar a escola, da sua construção à sua manutenção, como um lugar digno e apropriado ao desenvolvimento da alma, corpo e coração da criança, que precisava ter todo aparato moderno da civilidade, gerando, nos pequenos corações, o comprometimento cívico pátrio.

Castro (1900), no artigo "Higiene Escolar", chamou a atenção ao destacar a situação das escolas no Brasil e na capital paraense, principalmente no que se refere às escolas do interior do estado, e que algo precisava ser feito. Sobre as escolas do interior, o médico descrevia uma realidade escolar precária, como escolas com salas de aula sem iluminação, com pouca ou sem nenhuma ventilação, espaços tomados pela umidade, entre outras carências que destoavam do progresso veiculado pela República.

Além disso, no mesmo artigo, há enunciados que enalteciam o higienismo como ciência, um saber que, entre sua abrangência, poderia indicar a localização adequada de uma instituição de ensino para uma educação efetiva, como ambiente propicio à saúde coletiva: sem ruído, sem insalubridade, sem alagamentos. Em suma, situações em que a topografia do terreno não viesse a comprometer as condições de funcionamento escolar e, muito menos, seu endereço fosse próximo de atividades comerciais e industriais.

Somados aos elementos externos da escola, os materiais internos do prédio, no diagnóstico da higiene, não poderiam favorecer o acúmulo de micróbios e poeiras. A matrícula e a circulação de educandos no ambiente escolar ocorreria sob controle de exames de profissionais da saúde para que a instituição, destinada a formar o novo cidadão nos parâmetros civilizatórios e modernos no sistema Republicano, não viesse a ser um espaço de proliferação de doenças (CASTRO, 1900).

Essas ausências estruturais e físicas na educação, apontadas por Castro (1900, p. 24) em seu artigo dirigido à revista $A$ Escola, comprometiam a saúde daqueles que habitavam os espaços escolares, sobretudo, a saúde das crianças. Essa situação, para esse intelectual, decorria das más construções desses espaços que, no mais, colocavam a vida das crianças que ali estudavam sob o risco de "anemias, miopias, enxaquecas etc.".

Imbuído desse pensamento científico, o médico Acylino de Leão, colaborador da Revista do Ensino, destacou, em um artigo de título "Higiene Escolar", publicado na edição de no 08 da Revista do Ensino de 1912, "o racional é estabelecer o equilíbrio entre cultura intelectual e a 
cultura física, sabendo de antemão que a segunda é a base racional de toda educação" (LEÃO, 1911, p. 68).

O pensamento desse médico foi vital para a organização do projeto educacional do Pará, reproduzindo e formalizando saberes médicos e científicos para a ordem social posta pelo republicanismo no estado. Ele defendia a saúde da criança não apenas para garantir o progresso da nação, mas para a difusão de uma raça culta e de modos higiênicos. Com relação a isso o médico (LEÃO, 1911, p. 76) colocou:

Estudar as ciências, a aprender os que os outros descobriam, é realçar os limites do conhe-
cimento humano, é que em todas as épocas, foi considerado como a mais nobre e a mais
agradável das ocupações humanas ...>> A ciência torna a vida não só mais agradável, porém
mais útil, e um ser racional é obrigado, por todos os motivos de interesse e de dever, a diri-
gir seu espírito para pesquisas que conduzam tão seguramente à virtude como à felicidade.

A fala de Acylino de Leão, ao discursar sobre a seleção natural da humanidade, movido pela teoria Darwiniana, enaltecia uma higiene não apenas física, mas social na Revista do Ensino, na edição de no 02 de 1911, no artigo de título "Higiene Social". Nesse artigo, o médico defendeu que a evolução do saber científico permeou a vida humana, fornecendo ao homem a capacidade de evoluir de um estado selvagem, da rudez do trabalho da vida para um estado de inteligência, de culto à virtude e à beleza.

A pujança do saber intelectual científico, característico do positivismo republicano, deu as bases necessárias para que os discursos médicos assentassem o conhecimento científico como um saber dominante no ensino paraense. Com relação a esse ponto, havemos de corroborar com Stephanou (2011, p. 147), quando evidencia que os médicos desse período se viam como "aqueles que detinham um saber 'verdadeiro' e, por isso, o direito de falar sobre os modos de cultivar uma vida saudável”. Esse saber científico se diluía entres os discursos dos médicos que atuaram na orientação da educação primária do Pará.

Diante das discussões higienistas que estavam acontecendo no cenário republicano brasileiro, as instituições educativas passaram a se preocupar com a higiene dos seus espaços, para que assim pudessem oferecer a melhor educação para o estado. Escolas particulares normalmente anunciavam em jornais do estado que seus espaços estavam dentro dos padrões de higiene:

\footnotetext{
Collegio Santa Cecilia

41 - Rua Demetrio Ribeiro - 41

Este estabelecimento de instrução, completamente formado observando rigoroso ensino dos programas officiaes, primário e secundário, e tendo o maior cuidado com a hygiene e com a educação physica, moral e cívica, reabre as suas aulas no dia 3 de janeiro, recebendo alunos internos, semi internos e externos. [...].

Os diretores: Olegario Vela e Maria José Vela. (FOLHA DO NORTE, 1910, p. 02).
}

As instituições públicas também se preocupavam com a higiene, principalmente, por serem muito mais cobradas pelo Governo do Pará. O diretor João Alves de Paiva Menezes, diretor do $4^{\circ}$ grupo escolar José Verissimo, no seu relatório, comentou sobre a situação do prédio que sediava o grupo escolar. Era um local bem construído, com salas grandes e confortáveis, mas havia alguns problemas, como a falta de local adequado à prática da ginástica escolar. Para ele: 


\begin{abstract}
O Grupo funciona em edifício próprio, bem arejado, contendo amplas e confortáveis salas, onde se acham instaladas as aulas. Ressente-se, porém, de certos inconvenientes, tais como, sentinas colocadas em frente das aulas e falta de compartimentos apropriados para o recreio que, por isso, é dado nos corredores paralelos às salas de aulas nos quais as sentinas em número de 16. Seria conveniente aproveitar os pátios, ampliando-os e preparando-os de modo a poderem ser destinados ao repouso de espírito e exercícios físicos dos alunos; e quanto às sentinas, remove-las para outro lugar. (RELATÓRIO DO $4^{\circ}$ GRUPO ESCOLAR, 1909, p.8).
\end{abstract}

Observamos a preocupação do diretor em manter bem estruturado o edifício que sediava o Grupo Escolar. Convém-nos frisar que os Grupos Escolares passaram a ser referência de educação para as instituições particulares. Uma das principais preocupações que se tinha com as escolas estava relacionada às doenças. Naquela época, havia uma epidemia de febre amarela, tanto que se fez necessária uma campanha de combate a essa doença, realizada pelo ilustre Dr. Oswaldo Cruz, que era um dos mais conceituados médicos sanitaristas na área de combate às doenças contagiosas. Segundo Habib (2012, p. 61), a equipe coordenada por Oswaldo Cruz contava com dez médicos, quatro chefes de turmas, vinte capatazes, cinquenta guardas, um administrador e um escriturário, ao todo 86 homens, além de Oswaldo Cruz. O serviço foi realizado nos mesmos moldes em que foi feito na cidade do Rio de Janeiro.

Em todo território nacional, quando houvesse necessidade do combate a epidemias, o Governo local deveria expedir em lei esse ato para tornar conhecido a toda população. "O governo expedia os atos oficiais considerados indispensáveis. Eis a integra de tais documentos" (HABIB, 2012, p. 65):

Lei N. 1.140- de 5 de novembro de 1910

Autoriza o governador a promover, pelos meios que julgar convenientes, o serviço de profilaxia específica da febre amarela, e da outras providencias.

O Congresso Legislativo do Estado decretou e eu sanciono a seguinte lei:

Artigo $1^{\circ}$. - Fica o Governador do Estado Autorizado a promover, desde já, nesta capital, e pelos meios que julgar convenientes, o serviço de profilaxia específica da febre amarela. $\S 1^{\circ}$. Esse serviço será contratado com o eminente higienista brasileiro Dr. Oswaldo Gonçalves Cruz, que será o chefe da campanha sanitária, e se executará dentro do prazo de um ano.

Era clara a determinação do Governo em manter, principalmente, as suas crianças longe de doenças contagiosas. Por esse motivo, alunos acometidos de doenças graves não poderiam ser matriculados, sendo obrigatória a apresentação da carteira de vacinação, segundo o regulamento de 1910. De acordo com Habib (2012, p. 97), o trabalho do Dr. Oswaldo Cruz foi excelente, em apenas dezenove dias de atividade, ele já havia exterminado 9.973 focos de larvas do mosquito Aedes aegypti em Belém, hoje conhecido como transmissor do vírus da dengue.

Os Grupos Escolares foram palco de higienização de seus espaços educativos com o objetivo de preservar a saúde dos que neles trabalhavam e estudavam. Notícia veiculada no jornal Província do Pará (1910) destacou a desinfecção do prédio do 6 Grupo Escolar: "O diretor do Serviço Sanitário do Estado vai mandar proceder a uma limpeza e desinfecção no edifício onde funciona o $6^{\circ}$ grupo escolar da capital”. (PROVÍNCIA DO PARÁ, 1910, p.02). 


\section{Considerações FinaIS}

Entender o período da Primeira República tem mostrado vários ângulos diferentes, e esses se distinguem mais ainda quando analisamos mais profundamente uma região ou cidade especifica por exemplo. Em se tratando do Pará, no período republicano, foi possível percebermos uma grande diversidade social, visto que, na capital, tínhamos mais condições sociais e estruturais para uma boa educação e espaços escolares com mais condições higiênicas salutares, em contraponto aos interiores do estado, onde os prédios escolares eram na grande maioria inferiores aos da capital.

Discutir higienismo e educação no período republicano, de certa forma, é escancarar uma realidade social que poderia, naquele tempo, impedir ou não uma criança de ter acesso à educação. Como vimos, uma 'boa' saúde era essencial para a matrícula da criança nas instituições educativas do estado, caso contrário, essa criança poderia ficar até isolada.

Contudo, é importante frisarmos até que ponto o Estado dava condições para essa educação higiênica e higienizadora? Será que, de fato, as construções escolares, ao longo do estado do Pará, atendiam a todas essas medidas higiênicas que os discursos médicos e sanitaristas prescreviam? São perguntas que ainda têm muito a contribuir com as pesquisas históricas no Pará.

Os discursos médicos-sanitaristas apontavam que o poder público deveria direcionar seus discursos e ações para as regras de higiene, já que suas forças se direcionavam para aproximar a vida paraense aos padrões de vida civilizada dos países europeus e norteamericanos à modernização.

Os ideais científicos, direcionados para o âmbito escolar republicano, ditavam formas de reordenamento dos espaços escolares, como as salas de aula, que deveriam ser espaçosas, ventiladas, em escolas construídas sempre no centro do terreno onde funcionariam, distantes de fábricas ou qualquer outro espaço que lhes trouxesse o desconforto sonoro.

Esses discursos científicos faziam parte do rol das ideologias reafirmadas na República e acompanhavam o cenário civilizatório da nova pátria, regiam de certa forma não somente a disposição das escolas em termos estruturais, mas comunicavam ideais cientificistas para a educação, como formas de modelamento dos corpos que, nesse período, precisavam ser formados de modo sadio, não apenas em termos físicos, mas no espírito que se construía em apoio ao patriotismo da República. 


\section{REFERÊNCIAS BIBLIOGRÁFICAS}

4 GRUPO ESCOLAR. Relatório do ano de 1909 Belém: Typografia do Instituto Lauro Sodré, 1909.

A PROVÍNCIA DO PARÁ. Belém: Typographia d' O Futuro, 1910.

CASTRO, Germiniano de Lira. Higiene Escolar. A Escola, n² 2, Imprensa Oficial: Pará, outubro, 1900. p. 23-26.

COELHO, Geraldo Mártires. No Coração do Povo - O monumento à República em Belém 1891 1897. Belém: Paka Tatu, 2002.

ELIAS, Norbert. O processo civilizador: uma história dos costumes. Rio de Janeiro: Zahar, 1994a. v. 1.

FARIAS, William Gaia. A República no Pará: os primeiros momentos. In: SARGES, Maria de Nazaré dos Santos; RICCI, Magda de Oliveira (org.). Os oitocentos na Amazônia. Pará: Açaí, 2013. p. 183-205.

FOLHA DO NORTE. Belém: Typographia d'A Folha do Norte; 1910. p. 02.

FOUCAULT, Michel. A Arqueologia do Saber. Rio de Janeiro: Forense Universitária, 1986.

FRANÇA, Maria do Perpétuo Socorro G. S. A. José Veríssimo (1897-1916) e a Educação

Brasileira Republicana: raízes da renovação escolar conservadora. 2004. 173 f. Tese (Doutorado)

- Faculdade de Educação, Unicamp, Campinas, 2004.

GONDRA. José Gonçalves. Artes de civilizar: medicina, higiene e educação escolar na corte imperial. XXIII Simpósio Nacional de História, Londrina, 2005. p. 1-8. HABIB, F. N. Oswaldo Cruz e a febre amarela no Pará. - 2. ed., rev. e ampl. - Ananindeua: Instituto Evandro Chagas, 2012.

HABIB, F. N. Oswaldo Cruz e a febre amarela no Pará. 2. ed., rev. e ampl. -Ananindeua: Instituto Evandro Chagas, 2012.

HOFBAUER, Andreas. Raça se impõe. In: HOFBAUER, Andreas. Uma história de branqueamento ou o negro em questão. São Paulo: UNESP, 2006, p. 93-139.

LEÃO, Acylino. Educação. Revista do Ensino do Pará, no 2: Imprensa Oficial, Pará, 1911.

LOPES, Mário Allan da Silva. Vitrine da República: a educação de crianças no $5^{\circ}$ grupo escolar "Barão do Rio Branco" em Belém-Pa (1900-1912). 2018. 120 f. Dissertação (Mestrado Acadêmico em Educação) - Centro de Ciências Sociais e Educação, Universidade do Estado do Pará, Belém, 2018.

MEIRA, Clóvis Olinto de Bastos. Médicos de outrora no Pará. Belém: Grafisa, 1986.

MENDES, Maria Isabel B. de Souza; NÓBREGA, Terezinha P. da. O Brazil-Medico e as contribuições do pensamento médico-higienista para as bases científicas da educação física brasileira. História, Ciências, Saúde - Manguinhos, Rio de Janeiro, v.15, n.1, p.209-219, jan.-mar. 2008.

PARÁ. Mensagem dirigida ao Congresso Legislativo do Estado do Pará, pelo governador José Paes de Carvalho, em 02 de fevereiro de 1897. Belém. Diário Oficial, 1897.

PRIORE, Mary Del. Tempos de Mudanças e Medo. In: Histórias da Gente Brasileira. vol 3.

República - Memórias (1889-1950): LeYa, Rio de Janeiro, 2017. p. 19-26. 
SÁ, Dominichi Miranda de. A Ciência como Profissão: médicos, bacharéis e cientistas no Brasil (1895-1935). Rio de Janeiro: Fiocruz, 2006.

SANTOS, José A. Gouveia; ALVES, José J. de Alencar. O Curso Regente Agrícola como Introdutor das Ciências e Técnicas Modernas na Amazônia. Revista História da Ciência e Ensino: construindo interfaces. Volume 10, 2014, p. 19-38. Disponível em: <https://revistas.pucsp.br/ index.php/hcensino/article/view/17346>. Acesso em: 21 fev. 2020.

SANTOS, Darlene da Silva Monteiro; FRANÇA, Maria do Perpétuo Socorro G. S. A. A imprensa pedagógica e educação no Pará em dias de República: a revista A Escola e a Revista do Ensino como instituições de formação (1900-1912). Revista História da Educação, UFGRS, v. 20, p. 1-30, 2020 .

SANTOS, Darlene da Silva Monteiro. A arte de civilizar: a educação cívico patriótica na revista A Escola e na Revista do Ensino no Pará Republicano (1900-1912). Dissertação (Mestrado Acadêmico em Educação) - Centro de Ciências Sociais e Educação/Universidade do Estado do Pará, 2018.

SARGES, M. N. Belém: riquezas produzindo a Belle Époque (1870-1912). 3. ed. Belém: Paka-Tatu, 2010.

SOUSA, Célia Maria Paes de. Instituto Lauro Sodré: Instituição para Meninos Desvalidos no Pará. In: XII CONGRESSO NACIONAL DE EDUCAÇÃO 10, 2015. Curitiba. Anais [...]. Curitiba: EDUCERE, 2015. Disponível em: <http://educere.bruc.com.br/arquivo/pdf2015/20817_10731. pdf>. Acesso em: 18 mar. 2020.

STEPHANOU, Maria. Discursos Médicos e a Educação Sanitária na Escola Brasileira. In: STEPHANOU, Maria; BASTOS, Maria Helena Camara. (org.). Histórias e Memórias da Educação no Brasil. vol. III. Séc XX. 4 ed. Vozes, Petrópolis. Rio de Janeiro, 2011. p. 142-164. 